\title{
Evolution and Medicine
}

\author{
Kristin P. Jenkins • Michael F. Antolin
}

Published online: 17 December 2011

(C) Springer Science+Business Media, LLC 2011

\section{Evolution and Medicine}

The potential impact of an evolutionary approach to medicine and public health is enormous, informing areas of research and providing predictions and guidance for novel interventions. Conversely, evolutionary researchers have much to gain from exploring human health data. This convergence of evolution and medicine has been called "Darwinian medicine" and "evolutionary medicine," neither of which seems adequate to encompass the breadth and potential of the collaboration. The field has progressed substantially since the initial paper by Williams and Nesse (1991) and the book by Nesse and Williams (1994) Why We Get Sick, which provided a look at the evolutionary factors behind a variety of illnesses. Since then, researchers have applied an evolutionary approach to a broad range of health-related issues and successfully described many human phenotypes, both healthy and diseased, in terms of their evolutionary or ultimate causes. An overview of this work may be found in multi-authored volumes edited by Stearns and Koella (2007) and Trevathan et al. (2008), a special issue of PNAS (Stearns et al. 2010), and a recent textbook by Gluckman et al. (2009). The value of this insight cannot be overlooked in the ongoing battle with old and new pathogens, malfunctions of the human body such

\section{K. P. Jenkins $(\square)$}

National Evolutionary Synthesis Center,

2024 W. Main Street, Suite A200,

Durham, NC 27705, USA

e-mail: kjenkins@nescent.org

\section{F. Antolin}

Department of Biology, Colorado State University,

Fort Collins, CO 80523, USA

e-mail: michael.antolin@colostate.edu as cancer, and in addressing the health issues that plague industrial and post-industrial societies. For example, an evolutionary viewpoint is the only way to understand the spread of antibiotic resistance in bacteria and to develop effective methods for stopping or slowing it. Defining the evolutionary process of cancers is leading to new, more targeted approaches in cancer treatment. The obesity epidemic and associated metabolic syndromes may be best explained by the mismatch to modernity theory (Stearns and Koella 2008), an understanding that may lead to better prevention and treatment. An evolutionary approach to medical and public health problems can provide powerful insights and inspire novel solutions.

\section{Evolution and Medicine in the Classroom}

Recent reports touching on high school, undergraduate, premedical, and medical school education have emphasized the key role of evolutionary concepts in biology education (Labov 2011). Because evolution is the unifying theory of biology, it provides students a framework in which to organize biological information. An evolutionary approach is engaging because it allows students to ask how and why biological systems and organisms exist in their current forms, and raises awareness that the biological world is far from static. These are important understandings that prepare students to be scientifically literate citizens in a changing world.

Medical examples can be used in the classroom to engage a broad range of students, and to elucidate a number of basic evolutionary concepts (Nesse et al. 2010; Antolin et al. 2012). For example, common descent may be illustrated by the effectiveness of biomedical research with model organisms, the genotype to phenotype connection is 
demonstrated by variation in disease symptoms among individual patients, and the concept of environmentally influenced fitness is demonstrated in "diseases of the modern world." In addition, evolutionary medicine provides current topics to engage premedical and allied health students who may not see the practical application of basic evolutionary biology concepts.

Premedical and public health students, who will be in a position to apply this information throughout their professional careers, are often resistant to studying evolution. A report in this issue indicates that resistance extends beyond the U.S. (Yousuf et al. 2011). In part, this reflects the gulf between evolutionary research and medical research and practice. However, there is a growing movement to bridge the gap between these disciplines (Antolin et al. 2012, AAMC-HHMI 2009). A synthesis of evolutionary research and biomedical research has enormous potential to benefit and advance both areas of research, with the added benefit of immediate applications in medical and public health practices. One approach to bridging this gap is to introduce students to evolution in terms of human health. Exposure to examples from human health in terms of evolutionary concepts may help students looking toward a career in the health professions come to understand the unique insights of an evolutionary viewpoint. This has the twofold advantage of engaging students and contributing to the expectation that evolution has a role in medical studies.

\section{Resources for Teaching about Evolution and Medicine}

The goal of this issue was to provide faculty with both general information that would inform their use of this topic and offer specific examples and tools to use in the classroom. We begin with a statement from T. Meagher (2011), the Chair of the Education Committee for the Society for the Study of Evolution (SSE). Many of the articles in this issue are derived from a symposium on evolution and medicine at the Evolution 2011 meetings co-sponsored by SSE and the National Evolutionary Synthesis Center (Antolin et al. 2012). Labov (2011) of the National Academies of Science provides a policy overview of recent reports on high school, undergraduate, premedical, and medical education from NSF, AAAS, the College Board, and the AAAMC and HHMI. These reports converge on the ideas of emphasizing concepts rather than content, and all point to evolution as a key biological concept. Changes in the AP biology course and the MCATs will drive student expectations for thorough coverage of evolutionary biology, and the intersection between evolution and medicine provides engaging and informative examples of key evolutionary concepts.

This is supplemented by clinical experiences of medical doctors (Alcock and Schwartz 2011), demonstrating how evolutionary questions about medical issues can not only engage students, but help explain non-intuitive results and help provide a deeper explanation that brings together disparate areas of medical study. They suggest that an evolutionary understanding of disease and health has implications in clinical practice, public health, and biomedical research. An evolutionary approach is endorsed for public health students in Omenn's (2011) paper in which he describes the growing interest in public and global health and how understanding basic evolutionary concepts and processes can improve the efficacy of our public health efforts. The interaction of human culture and technology with infectious agents, diet and physical activity, climate change, and other causes of migrations is better understood in the framework of evolutionary processes.

Papers by Antolin (2011) and Buklijas et al. (2011) illustrate both the unity and historical conflicts between evolution and medicine. As fields of science, evolution, and medicine have provided benefits to both general knowledge and society, through their common interests in the life sciences. However, the relationship has not been seamless, and in many instances has been impacted by misconceptions and misapplications of science. Because societal preconceptions about evolution can hinder learning about evolution (Alters and Nelson 2002), directly facing how typological thinking, teleology, and the abuses of eugenics have hindered friendly synthesis between evolution and medicine will provide valuable content. But even more, history clearly points to multiple bridges that have crossed the gulf between evolution and medicine over the last centuries, and students should know about these.

To support faculty interested in developing entire courses or learning modules in more general biology and/or evolution classes, this issue includes several useful resources. Stearns (2011) shares his experience and expertise in developing a course on evolutionary medicine, including course overviews and topics for discussion. Beardsley et al. (2011) describe a newly developed module from BSCS and National Institutes of Health (NIH), in which students explore the evolutionary concepts of common ancestry and natural selection using medical examples such as lactase persistence in adulthood, antibiotic resistance, the conserved impacts of the Pax6 neural development gene, and sickle cell anemia in populations where malaria is endemic. This resource is available free from NIH (http://science-education.nih.gov/customers. nsf/HSEvolution.htm). Addressing the need to provide examples of the value of integrating evolutionary thinking to clinical training, Buklijas et al. (2011) provide case studies in scurvy and female reproductive tract cancers that demonstrate the value of evolutionary thinking in medical practice. These examples will be of interest to students in general, but are written with medical students in mind following a format and including information medical students will recognize. 
Two further pieces exemplify how applications of evolutionary biology can influence how therapies in medicine are designed. Hanley (2011) describes how the high mutation rates in viruses can be used to our advantage in designing and producing attenuated virus vaccines, but also work against us, as mutations that arise during vaccination campaigns may increase virulence or interact with other viruses. Understanding the evolutionary concepts behind viral fitness and its relationship to virulence is critical for avoiding vaccination strategies that may favor reversion to more virulent wild type viruses. Casás-Selves and DeGregori (2011) present an evolutionary overview of cancers and their treatment. Evolution of multicellularity required a balance between repressing cell proliferation while allowing cells to multiply and differentiate for body growth, healing, and maintenance. Cancer provides an excellent example of antagonistic pleiotropy, clearly demonstrating that fitness is based on reproductive success, not survival. Cancer also provides one of the clearest applications of evolutionary thinking to therapies. Viewing cancer as an evolutionary process resulting from natural selection between cell lineages within tissues and the changing "environments" within the body over time can lead to new treatments that avoid the evolution of chemotherapy resistance and metastasis. This information has clear value for premedical and medical students' understanding of the human body.

These papers and others in this issue provide background and ideas about how and why to introduce evolutionary examples of medicine in the classroom. We encourage readers to think of ways that medical examples may be used to increase student understanding of basic evolutionary concepts, and also to consider collaborations in their own research and teaching that cross the disciplinary borders between evolution and medicine.

Acknowledgments The authors would like to thank Niles and Gregory Eldredge for inviting this special issue. We would also like to thank our colleagues, both authors and reviewers, who contributed their time and expertise to this issue.

\section{References}

AAMC-HHMI. Scientific Foundations for Future Physicians. American Association of Medical Colleges and Howard Hughes Medical Institute, Washington, DC; 2009
Alcock J, Schwartz MD. A clinical perspective in evolutionary medicine: what we wish we had learned in medical school. EVOO-D-11-00035R1; 2011 (in press)

Alters BJ, Nelson CE. Teaching evolution in higher education. Evolution. 2002;56:1891-901.

Antolin MF. Evolution, medicine, and the Darwin Family. EVOO-D11-00070; 2011 (in press)

Antolin MF, Jenkins KP, Bergstrom CT, Crespi BJ, De S, Hancock A, Hanley KA, Meagher TR, Moreno-Estrada A, Nesse RM, Omenn G, Stearns SC. Evolution and medicine in undergraduate education: a prescription for all biology students. Evolution. 2012 (in press)

Asfandyar Yousuf, Muhammad Ahmad bin Daud, Amina Nadeem. Evolutionary medicine: awareness \& acceptance in medical students. EVOO-D-11-00062; 2011 (in press)

Beardsley P, Stuhlsatz MAM, Kruse RA, Eckstrand IA, Gordon SD, Odenwald WF. Evolution and medicine: an inquiry-based high school curriculum supplement. EVOO-D-11-00037R1; 2011 (in press)

Buklijas T, Low FM, Beedle AS, Gluckman PD. Developing a curriculum for evolutionary medicine: case studies of scurvy and female reproductive tract cancers. EVOO-D-11-00031; 2011 (in press)

Casás-Selves M, DeGregori J. How cancer shapes evolution, and how evolution shapes cancer. EVOO-D-11-00038R1; 2011 (in press)

Gluckman P, Beedle A, Hanson MA. Principles of evolutionary medicine. Oxford, UK: Oxford University Press; 2009.

Hanley KA. The double-edged sword: How evolution can make or break a live-attenuated virus vaccine. EVOO-D-11-00040R1; 2011 (in press)

Labov JB. Evolutionary medicine and the medical school curriculum: meeting students along their paths to medical school. EVOO-D11-00070; 2011 (in press)

Meagher TR. The society for the study of evolution and evolutionary medicine. EVOO-D-11-00081; 2011 (in press)

Nesse RM, Williams GC. Why we get sick: the new science of Darwinian medicine. New York: Times Books, New York; 1994.

Nesse RM, Bergstrom CT, Ellison PT, Jeffrey S, Flier JS, Gluckman P, Govindaraju DR, Niethammer D, Omenn GS, Perlman RL, Schwartz MD, Thomas MG, Stearns SC, Valle D. Making evolutionary biology a basic science for medicine. Proc Natl Acad Sci USA. 2010;107:1800-7.

Omenn GS. Enhancing the teaching of evolution in public health. EVOO-D-11-00065; 2011 (in press)

Stearns SC, Koella JC, editors. Evolution in health and disease, 2nd edition. New York: Oxford University Press; 2007.

Stearns SC, Koella JC. Eds. Oxford University Press: Evolution in health and disease; 2008.

Stearns SC. On designing courses in evolutionary medicine. EVOOD-11-00027R1; 2011 (in press)

Stearns SC, Nesse RM, Govindaraju DR, Ellison PT. Evolution in health and medicine. Sackler Colloquium: evolutionary perspectives on health and medicine. Proc Natl Acad Sci USA. 2010;2010 (107):1691-5.

Trevathan W, Smith EO, McKenna JJ. Evolutionary medicine and health: new perspectives. New York: Oxford University Press; 2008.

Williams GC, Nesse RM. The dawn of Darwinian medicine. Q Rev Biol. 1991;66:1-22. 